\title{
An elevated level of copper zinc superoxide dismutase fails to prevent oxygen induced retinopathy in mice
}

\author{
Corina Klaeger, Luis de Sa, Andres J Klaeger, Elaine J Carlson, William V Good, \\ Charles J Epstein
}

\begin{abstract}
Background-To determine whether a higher level of copper zinc superoxide dismutase (CuZnSOD) can reduce the severity of oxygen induced retinopathy (OIR) in a mouse model.

Methods-CuZnSOD transgenic mice with a threefold increase in CuZnSOD activity and control non-transgenic mice were exposed to $90 \%$ oxygen for 12 hours a day during the first 5 days of life. After oxygen treatment, all mice were reared in room air for 10 days. Another group of transgenic and non-transgenic mice were kept in room air for 15 days and served as control groups for the oxygen effect. At day 15, all mice were killed and perfused with India ink. The retinas were flat mounted on slides and examined with a light microscope.
\end{abstract}

Results-There was a statistically significant increase in the incidence of OIR in mice exposed to high levels of oxygen, whether or not they were transgenic. However, there was no statistically significant difference in the severity of OIR between oxygen treated transgenic and non-transgenic mice.

Conclusion-A threefold higher CuZnSOD activity does not protect against OIR in mice. This is an unexpected finding, since oxygen radicals are considered a major factor causing OIR, and increased CuZnSOD activity has reduced oxygen radical induced damage in several neuronal and non-neuronal systems. The possibility of a damaging role for other radicals not affected by CuZnSOD cannot be excluded.

(Br f Ophthalmol 1996; 80: 429-434)

Although the cause of retinopathy of prematurity (ROP) in humans is not completely understood, oxygen therapy is one well recognised risk factor. ${ }^{1-3}$ However, there are many other risk factors, including prematurity, ${ }^{4}$ low birth weight, ${ }^{34}$ anaemia, ${ }^{5}$ blood transfusion, ${ }^{6}$ and acidosis. ${ }^{7}$ The exact relation of oxygen treatment to ROP is vague. ${ }^{38} \mathrm{~A}$ high partial pressure $\left(\mathrm{PO}_{2}\right)$ of oxygen may cause $\mathrm{ROP}$, but even when oxygenation is closely monitored, ROP still occurs. ${ }^{9}$ Fluctuating tissue oxygen levels may also play a role. ${ }^{10}$

Oxygen can damage tissue through the oxidative effect of oxygen radicals. A possible mitigating effect of antioxidants on ROP has been explored in studies examining vitamin $\mathrm{E}^{11} 12$ and serum bilirubin levels. ${ }^{13}$ Superoxide dismutase (SOD) is also involved in the metabolism of oxygen free radicals, catalysing the dismutation of $\mathrm{O}_{2}{ }^{-}$to $\mathrm{H}_{2} \mathrm{O}_{2}$. Since no case of ROP has ever been reported in infants with trisomy 21 (Down syndrome), in whom the activity of CuZnSOD is increased $1 \cdot 5$-fold, we postulated that $\mathrm{CuZnSOD}$ may exert a protective role against the development of ROP.

Transgenic mice have been bred which carry one or more copies of the human CuZnSOD gene. ${ }^{14}$ These animals have elevated activities of CuZnSOD, and we have used them to determine whether $\mathrm{CuZnSOD}$ can protect against experimental oxygen induced retinopathy (OIR).

\section{Methods}

All experiments were approved by the Committee for Animal Research, University of California, San Francisco, USA.

\section{TRANSGENIC MICE}

Heterozygous transgenic mice of strain TgHS/SF-218/3 carrying eight copies of the human $\mathrm{CuZnSOD}$ gene were derived from the founder stock described by Epstein et $a l,{ }^{14}$ and maintained on an outbred CD-1 background. When bred with CD-1 mice, half the offspring are transgenic and half are non-transgenic according to Mendelian inheritance. Transgenic mice are identified by qualitative demonstration of human $\mathrm{CuZnSOD}$, using non-denaturing gel electrophoresis followed by nitroblue tetrazolium staining. ${ }^{14}$ There are no obvious morphological or behavioural differences between transgenic animals and their normal non-transgenic litter mates. Gel electrophoresis assay of the retina of these transgenic mice reveals a pattern of transgene expression (data not shown) which is consistent with the three times normal activity of 
Table 1 Numbers of mice analysed

\begin{tabular}{lll}
\hline & Room air treated & Oxygen treated \\
\hline Non-transgenic & 17 & 41 \\
SOD-transgenic & 17 & 37 \\
\hline
\end{tabular}

CuZnSOD in brain and red cells determined by direct enzymatic analysis. ${ }^{14}$

\section{OXYGEN TREATMENT}

A total of eight litters of mice were housed in Plexiglas chambers flushed continuously with oxygen from a liquid source $(0.5 \mathrm{litre} / \mathrm{min})$ and maintained at sea level atmospheric pressure. The oxygen concentration was monitored with a calibrated oximeter twice daily and maintained at levels between $90 \%$ and $95 \%$ oxygen. The mice were kept in hyperoxia for 12 hours per day for 5 days, beginning immediately after birth. The mice were kept for the rest of the time in room air. Lighting was on a 12 hour on/off cycle and food and water were provided ad libitum. After oxygen treatment, the mice were kept in room air until day 15. Four litters of mice not exposed to hyperoxia were kept in room air until day 15 to serve as a control group.

\section{INDIA INK INJECTION}

On day 16 , the mice were deeply anaesthetised with $0.2 \mathrm{ml}$ pentobarbitone intraperitoneally and perfused with $2 \mathrm{ml}$ filtered, undiluted India ink (Whatman No 1) through the left ventricle, without previous rinsing of the circulatory system. The perfusion was done by hand with a $3 \mathrm{ml}$ syringe and 27 gauge needle over 30-50 seconds until the tip of the tail turned black. Immediately before perfusion, a blood sample was taken for genotyping by SOD gel electrophoresis. The mice were killed. After removal of the skin, the head was removed and fixed for 48 hours in $4 \%$ paraformaldehyde/ $0 \cdot 1 \mathrm{M}$ phosphate buffer, $\mathrm{pH} 7 \cdot 4$.

\section{RETINA FLAT MOUNTS}

To harvest the retina, the eye was left in the orbit while the cornea, iris, and lens were removed. Four cuts from the periphery to the posterior pole were then placed at the $12,3,6$, and 9 o'clock positions in the retina and the retina was removed using two soft brushes and light pressure from outside the globe. The isolated retinas were flat mounted on subbed slides ( $5 \%$ gelatin), the remaining vitreous and hyaloid artery systems were carefully removed using a soft brush, and the retinas were covered with Permount and a cover slip.

The mice whose retinas could be flat mounted were assigned to four groups according to their SOD status and oxygen exposure (Table 1). Rearing of the mice, perfusion with India ink, and the flat mounting led to some loss of mice or eyes. This loss was equally distributed in the four groups.

\section{SCORING OF OIR}

One of us (AJK) examined the retinas in a blinded fashion using a light microscope. Each quadrant of each retina was given a score ranging from 0 (normal appearance) to 2 (most severe OIR change) for each of the following four criteria:

\section{Primordial vessels}

Score $=0$ : mature capillary network. Polygonal meshwork of primordial vessels either absent or confined to the ora serrata (Fig 1).

Score $=1$ : equally sized areas of mature capillaries and primordial vessels (Fig 2).

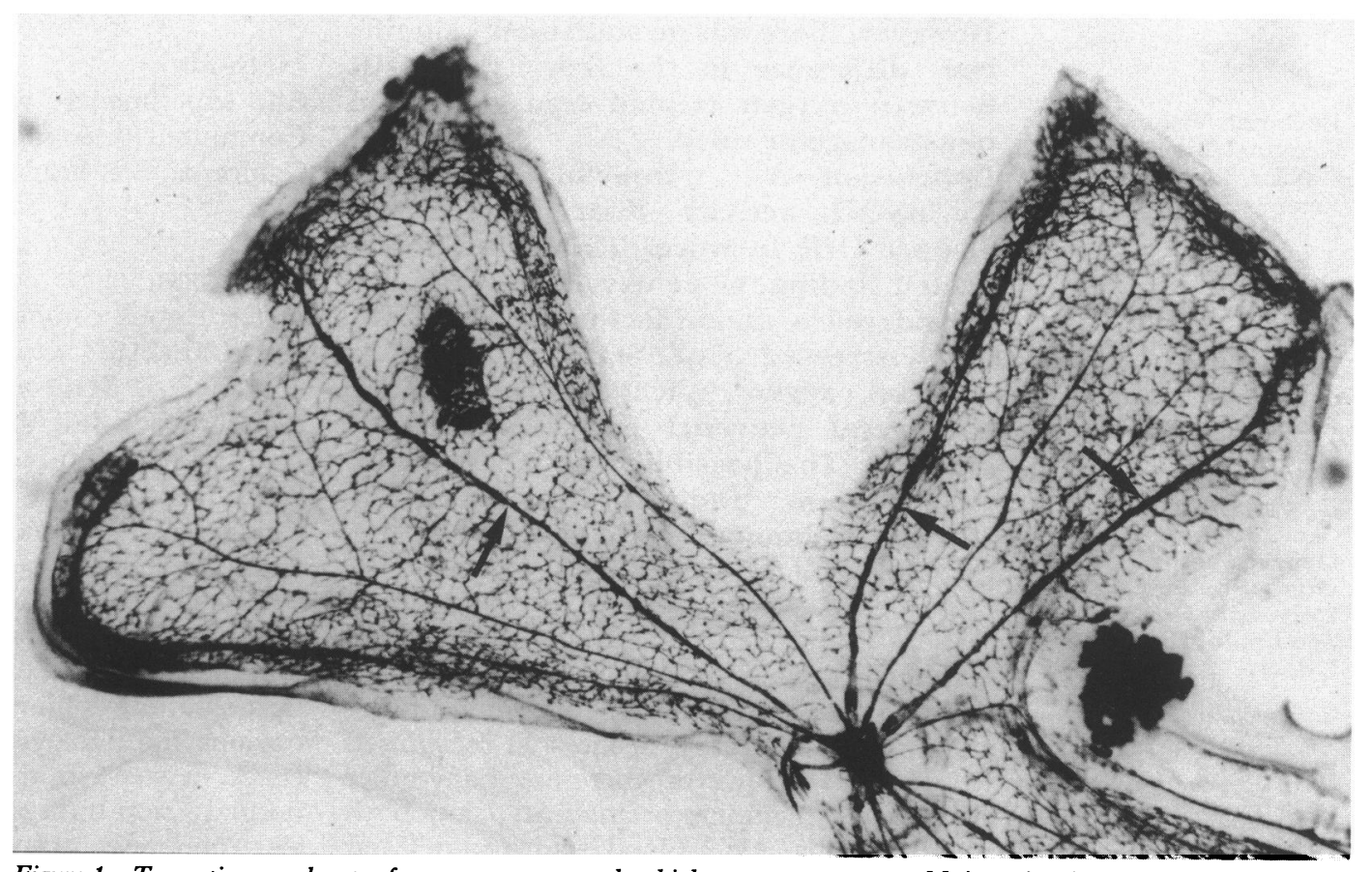

Figure 1 Two retina quadrants of a mouse not exposed to high percentage oxygen. Major veins (arrows) extend to ora serrata without gross changes in calibre (vein score $=0$ ). There are no capillary-free zones (capillary-free zone score $=0$ ). The capillary network is mature except for a few primordial vessels (arrows) confined to ora serrata (primordial vessel score $=0)$. The two black areas are artefacts. Magnification $\times 65$. 


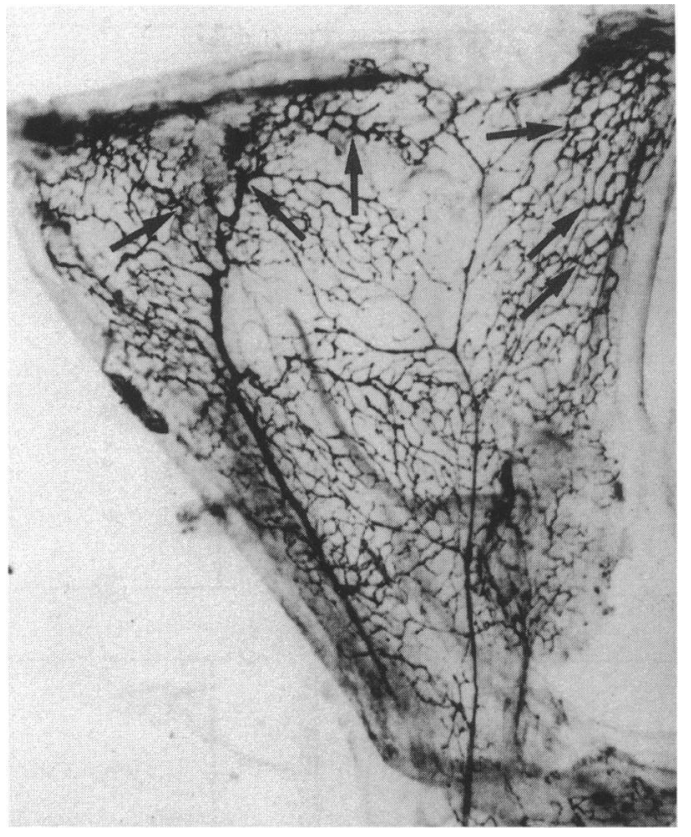

Figure 2 Retina quadrant of a mouse exposed to high percentage oxygen. Major vein exhibits only mild calibre changes and branches into sinusoid primordial vessels (arrows) in the peripheral half of retina (vein score=1). One distinct capillary-free zone smaller than a quarter quadrant lies in the mid-periphery (capillary-free zone score $=1$ ). Areas of mature capillary network and primordial vessels are about equal (primordial vessel score $=1$ ). Magnification $\times 65$

Score $=2$ : predominating polygonal meshwork of sinusoid primordial vessels (Fig 3).

\section{Appearance of major veins}

Score $=0$ : radical pattern of major veins without change in calibre. Branching only in the region of the ora serrata. The smaller veins, which do not reach the ora, arborise into a mature capillary network (Fig 1).

Score $=1$ : mild change in calibre of major veins. Branching into sinusoid vessels in the peripheral half of the retina (Fig 2).

Score $=2$ : severe change in calibre of the veins. The larger veins branch into sinusoid vessels in the central half of the retina (Fig 3).

3 Capillary loops connecting the superficial with the deep capillary layer

Score $=0$ : abundant capillary loops.

Score $=1$ : sparse or irregularly distributed capillary loops were present in the quadrant.

Score $=2$ : a few scattered or no capillary loops.

\section{Capillary-free zones}

Score $=0$ : no capillary-free zones (Fig 1).

Score $=1$ : one capillary-free zone less than a quarter in size (Fig 2).

Score $=2$ : one capillary-free zone larger than a quarter in size, or several smaller capillaryfree zones.

\section{STATISTICAL ANALYSIS}

For each criterion, we calculated the mean score over both eyes in an individual mouse by summing the scores of the quadrants that could be read and dividing by the number of evaluated quadrants. The minimum number of quadrants to qualify as a basis for the final mean score was set at four per mouse. The Wilcoxon rank sum test was used to compare the scores for each criterion between pairs of different groups.

\section{Results}

\section{OXYGEN INDUCED RETINOPATHY (OIR)}

The results of all experiments are summarised in Figure 4. After oxygen exposure, we observed several vascular changes in the retina. Most striking was the altered pattern of the major retinal veins. Instead of extending from the disc to the ora serrata in a straight fashion, as was seen in mice not exposed to oxygen, the veins arborised early and irregularly. Sometimes there were gross changes in the calibre of the vessels (Fig 3).

Capillary-free zones were observable in the periphery of the retina, and less often around the disc. A sinusoid small vessel pattern, the so called primordial vessels, is predominant before the adult-type capillaries appear. ${ }^{15}$ After oxygen exposure, the primordial vessels tend to persist and to show pronounced changes in calibre.

The deep capillary bed develops after the superficial capillary bed and is connected to the superficial bed by numerous loops. These loops, which reflect the extent of the deep capillary layer, can be partially missing in OIR. Vitreous haemorrhage occurred in three mice, one transgenic and two non-transgenic.

We found a significant difference in OIR between the oxygen exposed animals and the

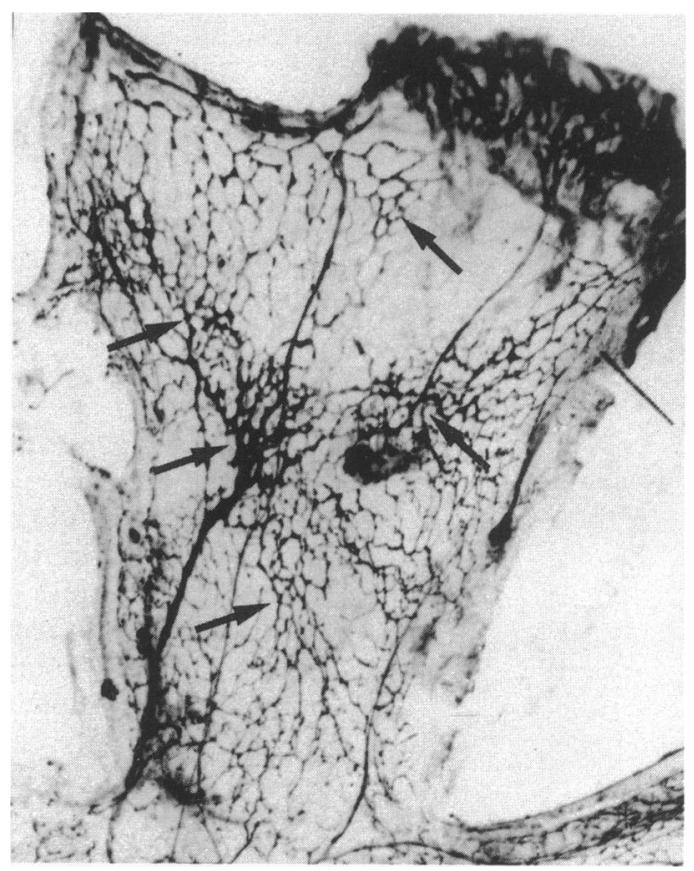

Figure 3 Retina quadrant of a mouse exposed to high percentage oxygen. Major vein shows marked change in calibre and branches into sinusoid primordial vessels (arrows) in mid-periphery of the retina (vein score $=2$ ). Several capillary-free zones are scattered in the central and peripheral half of the retina (capillary-free zones score $=2$ ). $A$ meshwork of sinusoid primordial vessels is predominant (primordial vessel score $=2$ ). Remnants of the well vascularised ciliary body appear as a black border at the ora serrata. Magnification $\times 65$. 
Figure 4 Summary of results of all experiments involving CuZnSOD transgenic mice and oxygen treatment. The size of each point is proportional to the number of observations with the indicated score.
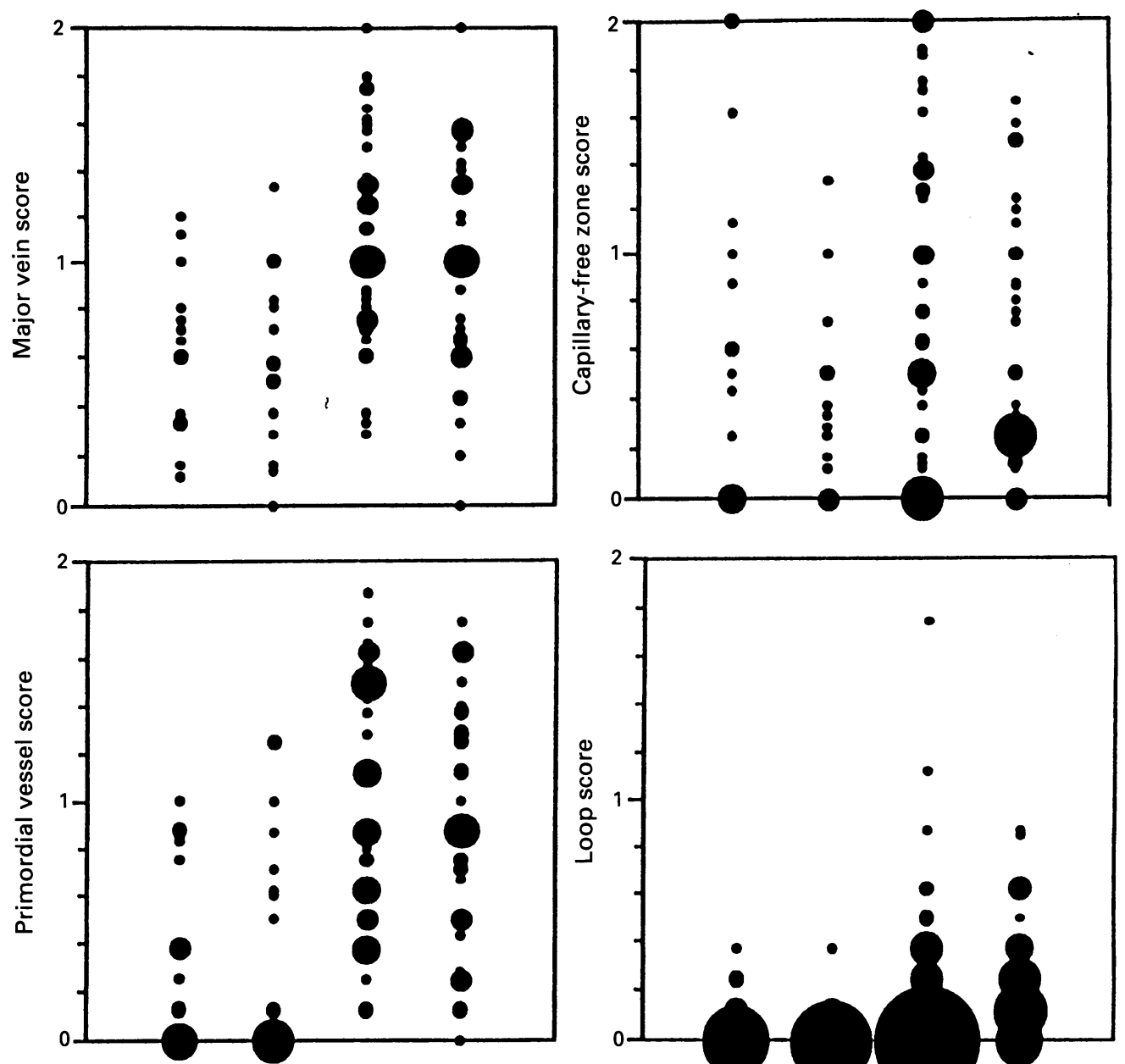

SOD transgene Oxygen treatment -

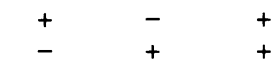

room air exposed animals, whether they were transgenic or non-transgenic. The $p$ values were $\leqslant 0.05$ for the three criteria: the presence of primordial vessels, the appearance of major veins, and the disruption of loops connecting the two capillary layers. The $p$ value for the capillary-free zone was marginally significant $(0 \cdot 06)$ in the transgenic group, and not significant $(0.49)$ in the non-transgenic group.

\section{EFFECT OF SOD}

When the oxygen exposed non-transgenic and transgenic mice were compared, we could not find a statistically significant difference in OIR for any of the criteria. Likewise, there was no difference in retinal appearance between the transgenic and non-transgenic control groups exposed only to room air. The $\mathrm{p}$ values are summarised in Table 2.

\section{Conclusion}

We demonstrated an oxygen effect (OIR) on the developing retinal vasculature in the non-transgenic and SOD transgenic mice. Abnormalities of the major veins and persistence of primordial vessels differentiated best between room air exposure and oxygen exposure (all $p$ values $\leqslant 0 \cdot 01$ ). Capillary loops that connect the superficial with the deep capillary layer were also affected by oxygen exposure. Three mice in

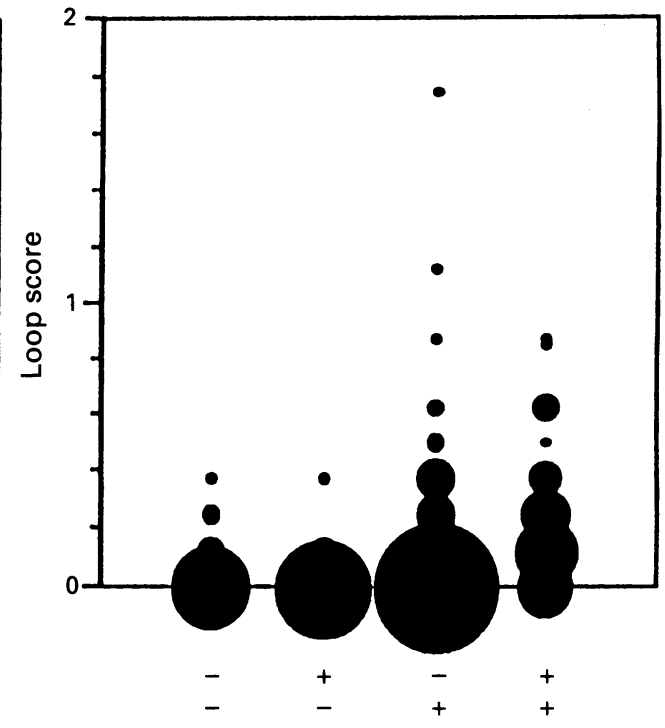

the oxygen exposed group had vitreous haemorrhages, two in non-transgenic mice and one in a SOD transgenic mouse. These numbers are too small for statistical comparison.

\section{Discussion}

If an important cause of OIR in animal models or ROP in humans is the toxic effect of oxygen radicals, interventions that alter the production or effects of oxygen radicals would be expected to affect the severity and incidence of OIR or ROP. All aerobic organisms possess a complex array of enzymatic and non-enzymatic antioxidant defences. Many randomised and controlled studies have been undertaken to assess the efficacy of prophylactic supplements of vitamin $\mathrm{E}$ in $\mathrm{ROP}^{12}$ but its effect on incidence or severity remains controversial. ${ }^{1617}$ Similarly, there have been conflicting reports regarding a beneficial role for bilirubin. ${ }^{13} 18-20$ SOD is known to convert the superoxide radical to hydrogen peroxide and oxygen, while the hydrogen peroxide is metabolised by catalase and glutathione peroxidase. The retina's antioxidant system may also extend to vitamin $\mathrm{C}$ and glutathione. Mn-SOD found in mitochondria is also active in the mouse retina, at least to 2 weeks of age. ${ }^{21}$

Transgenic mice of strain $218 / 3$ and of a very similar strain, $218 / 10$, both with elevations of CuZnSOD to about three times 
Table 2 p Values from the Wilcoxon rank sum test

\begin{tabular}{|c|c|c|c|c|}
\hline & $\begin{array}{l}\text { Primordial } \\
\text { vessels }\end{array}$ & $\begin{array}{l}\text { Major } \\
\text { veins }\end{array}$ & $\begin{array}{l}\text { Loops to deep } \\
\text { capillary layer }\end{array}$ & $\begin{array}{l}\text { Capillary- } \\
\text { free zones }\end{array}$ \\
\hline 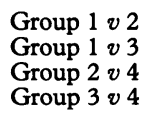 & $\begin{array}{c}1.0 \\
<0.001 \\
0.002 \\
0.4\end{array}$ & $\begin{array}{c}0.71 \\
<0.001 \\
0.01 \\
0.4\end{array}$ & $\begin{array}{c}0.43 \\
0.05 \\
<0.001 \\
0.28\end{array}$ & $\begin{array}{l}0 \cdot 24 \\
0 \cdot 49 \\
0 \cdot 06 \\
0 \cdot 7\end{array}$ \\
\hline
\end{tabular}

Group 1 =room air treated, non-transgenic; group 2=room air treated, SOD-transgenic; group $3=$ oxygen treated, non-transgenic; group 4=oxygen treated, SOD-transgenic.

non-transgenic levels, have been shown to be partially or completely protected against the toxic effects of various physical and chemical agents presumed to induce acute oxidative stress with the production of oxygen free radicals. In the nervous system, the sources of oxidative stress have included freezing, blunt trauma, ischaemia and reperfusion, and injection of $N$-methyl-4-pheny-1,2,3,6-tetrahydropyridine (MPTP) and methamphetamine. ${ }^{22-26}$ The sources of stress outside the nervous system have been streptozotoxin and alloxan (which cause islet cell degeneration and diabetes mellitus) and tumour necrosis factor (which kills bone marrow progenitors). ${ }^{27} 28$ Protection against hyperoxia, with regard to pulmonary toxicity, is also documented in another transgenic strain with similar CuZnSOD activity. ${ }^{29}$ Based on these precedents, it seems reasonable to expect that other pathological processes in which oxygen free radicals are involved may also be ameliorated in CuZnSOD transgenic animals. However, we did not demonstrate a protective effect against OIR of increased SOD levels in newborn mice exposed to hyperoxia. And, the incidence and severity of OIR in non-transgenic and transgenic mice did not differ significantly. This is an unexpected finding, since one major factor causing OIR is thought to be oxygen radicals. ${ }^{30}$ To be fair, there are several other possible explanations for this finding. The first is that the pathogenesis of OIR either does not involve oxygen radicals, or, if it does, that the concentrations of oxygen radicals generated are not sufficiently affected by the increased level of SOD present in transgenic mice, or that other types of radicals unaffected by $\mathrm{CuZnSOD}$ are aetiological. In this regard, it is important to note other experimental systems in which increased CuZnSOD activity was not protective. In a perinatal hypoxia-ischaemia model, brain injury was, in fact, exacerbated, possibly because there was insufficient glutathione peroxidase activity to handle an increased generation of hydrogen peroxide. ${ }^{31}$ In addition, Smith et al reported that elevated levels of CuZnSOD appeared to increase retinal neovascularisation in a mouse model of oxygen induced retinopathy. ${ }^{32}$ It has been suggested that effective organism defence against reactive oxygen may require balanced increments in antioxidant enzymes that may not necessarily be improved by increases in the activity of single enzymes. ${ }^{33}$

Another possible reason for lack of protection by the elevated SOD activity is that the degree of OIR produced in this study was not at the correct threshold to demonstrate a SOD effect. However, intermittent oxygen exposure results in more pronounced OIR in mice and rats, especially when combined with intermittent hypoxia. ${ }^{34-36} \mathrm{We}$ chose intermittent exposure to oxygen for this reason and for the safety of the adult mice. Other types of exposure (for example, constant, prenatal) could have led to different results, but the mortality rate for pups would have been much higher.

A characteristic of ROP is the initial arrest of the normal development of vessels growing out to the ora serrata and not the vaso-obliteration of already existing capillaries. ${ }^{37}$ It is conceivable that the pathogenesis of OIR may be different from that of ROP and may not require oxygen radical formation for damage to occur. It is clearly possible to damage and obliterate already existing capillaries of the retina (and other organs) with a toxic oxygen concentration in many types of animals. In the newborn kitten, oxygen induced vaso-obliteration leads to an ischaemic vasoproliferative retinopathy. ${ }^{38}$ Prolonged hyperoxia produces lung oedema in adult mice. ${ }^{29}$ If vaso-obliteration is the driving force for proliferative retinopathy, then OIR in an experimental animal may not exactly model ROP in humans.

OIR in mice has been studied previously. ${ }^{17} 34$ 39-44 In our study, with induction of a mild OIR, the most consistent findings were abnormalities of the major veins and the persistence of primordial vessels. We did not find substantial amounts of capillary-free zones which would make a clear distinction between oxygen exposure and room air exposure. One explanation for this is the nature of the oxygen treatment in this study. We wanted to induce a mild OIR, which might show a greater sensitivity to a varying parameter (SOD) than would a severe OIR.

Another explanation for no CuZnSOD effect may be the use of India ink. Fluoresceindextran perfusions have been reported to result in better total retinal vascular visualisation. ${ }^{44}$ Also, there is sometimes interference from artefacts resulting from the flat mount preparation. In the attempt to brush away the hyaloid artery system, it is possible to damage the fine superficial capillary net which could lead to false capillary-free zones. Nevertheless, we showed a statistically significant effect on retinal vascularisation in the oxygen versus room air exposed mice.

Our OIR findings suggest that the main oxygen effect is a delay and disorganisation of the normal development of the retinal vasculature, in that the primordial vessels tend to persist and that the major veins tend not to reach their full extension in regions where they develop last - that is, in the deeper retinal layer and in the periphery of the retina, as well as around the disc. A similar observation was made by Michaelson et al, ${ }^{40}$ that hyperoxia in newborn mice leads to a prominent delay in the formation of the capillary bed situated around the disc. Ashton ${ }^{17}$ regarded the oxygen tension within the tissue as the key controlling factor for the budding capillaries to wax and wane according to the needs of the tissue. High oxygen tension in the retina could reduce the 
normal stimulus for the vasculature to grow in a newborn animal's retina, despite oxygen radical injury. The retina is left ischaemic when returned to normal oxygen levels (or hypoxia). In that setting, oxygen radical scavengers would not prevent OIR.

This work was supported in part by NIH grant AG-08938 to CJE, by a grant from the Lucille $P$ Markey Charitable Trust to the UCSF Program in Biological Sciences, by That Man May See, Inc and Research to Prevent Blindness, New York City.

1 Patz A, Hoeck KE, DeLa Cruz E. Studies on the effect of high oxygen administration in retrolental fibroplasia. I. hursery observations. Am $f$ Ophthalmol 1952; 35: 1248-53.

2 Kinsey VE. Retrolental fibroplasia. Cooperative study of retrolental fibroplasia and the use of oxygen. $A m \mathcal{F}$ Ophthalmol 1956; 56: 481-543.

3 Kinsey VE, Arnold HJ, Kalina RE, Stern L, Stahlman M, Odell $\mathrm{G}$, et al. $\mathrm{PaO}_{2}$ levels and retrolental fibroplasia: a report of the cooperative study. Pediatrics 1977; 60: 655-68.

4 Flynn JT. Acute proliferative retrolental fibroplasia: multivariate risk analysis. Trans Am Ophthalmol Soc 1983; 81: 549-91.

5 Majima A. Studies on retinopathy of prematurity 1 Statistical analysis of factors related to occurrence and progression in active phase. Fpn $\mathcal{f}$ Ophthalmol 1977; 21: 404-20.

6 Sacks LM, Schaffer DB, Anday EK, Peckham GJ, Delivoria-Papadopoulos $M$. Retrolental fibroplasia and blood transfusion in very low-birth-weight infants. Pediatrics 1981; 68: 770-4.

7 Bossi E, Koerner F, Zulauf M. Retinopathy of prematurity: risk factors - a statistical analysis of matched pairs. Retinopathy Prematurity Conference 1981; 2: 536-9.

8 Silverman WA. Retinopathy of prematurity: oxygen dogma challenged. Arch Dis Child 1982; 57: 731-3.

9 Bancalari E, Flynn JT, Goldberg RN, Bawol R, Cassady J, Schiffman J. Influence of transcutaneous oxygen monitoring on the incidence of retinopathy of prematurity. Pediatrics 1987; 79: 663-9.

10 Flynn JT, Bancalari E, Snyder ES, Goldberg RN, Feuer W, Cassady J. A cohort study of transcutaneous oxygen tension and the incidence and severity of retinopathy of prematurity. N Engl f Med 1992; 326: 1050-4.

11 Phelps DL. Vitamin E and retrolental fibroplasia in 1982. Pediatrics 1982; 70: 420-5.

12 Muller DPR. Vitamin E therapy in retinopathy of prematurity. Eye 1992; 6: 221-5.

13 Gaton DD, Gold J, Axer-Siegel R, Wielunsky E, Naor N, Nissenkorn I. Evaluation of bilirubin as possible protective factor in the prevention of retinopathy of prematurity. Br $\mathcal{F}$ Ophthalmol 1991; 75: 532-4.

14 Epstein CJ, Avraham KB, Lovett $M$, Smith E, Elroy-Stein $O$, Rotman G, et al. Transgenic mice with increased Cu/Zn-superoxide dismutase activity: animal model of dosage effects in Down syndrome. Proc Natl Acad Sci USA 1987; 84: 8044-8.

15 Connolly SE, Hores TA, Smith LE, D'Amore PA. Characterization of vascular development in the mouse Characterization of vascular developm

16 Penn JS, Thum LA, Naash MI. Oxygen-induced retinopathy in the rat. Vitamin $C$ and $E$ as potential therapies. Invest Ophthalmol Vis Sci 1992; 33: 1836-45.

17 Ashton N. Some aspects of the comparative pathology of oxygen toxicity in the retina. $\mathrm{Br} F$ Ophthalmol 1968; 52: 505-31

18 Heyman E, Ohlsson A, Girschek P. Retinopathy of prematurity and bilirubin. N Engl ₹ Med 1989; 320: 256

19 Boynton BR, Boynton CA. Retinopathy of prematurity and bilirubin. $N$ Engl f Med 1989; 321: 193-4

20 Fauchère J-C, Meier-Gibbons FE, Koerner F, Bossi E Retinopathy of prematurity and bilirubin - no clinical evidence for a beneficial role of bilirubin as a physiological antioxidant. Eur $\mathcal{F}$ Pediatr 1994; 153: 358-62.

21 Yamashita H, Horie K, Yamamoto T, Katagiri H, Asano T, Hirano T. Superoxide dismutase in developing mouse retina. Ipn f Ophthalmol 1994; 38: 148-61.

22 Chan PH, Yang GY, Chen SF, Carlson E, Epstein CJ. Cold-induced brain edema and infarction are reduced in transgenic mice overexpressing $\mathrm{CuZn}$-superoxide dismutase. Ann Neurol 1991; 29: 482-6.

23 Kinouchi H, Epstein CJ, Mizui T, Carlson E, Chen SF, Chan PH. Attenuation of focal cerebral ischemic injury in transgenic mice overexpressing $\mathrm{CuZn}$ superoxide dismutase. Proc Natl Acad Sci USA 1991; 88: 11158-62.

24 Przedborski S, Kostic V, Jackson-Lewis V, Naini AB, Simonetti S, Fahn S, et al. Transgenic mice with increased $\mathrm{Cu} / \mathrm{Zn}$-superoxide dismutase activity are resistant to $\mathrm{Cu} / \mathrm{Zn}$-superoxide dismutase activity are resistant to N-methyl-4-phenyl-1,2,3,6-tetrahydropyridi

25 Cadet JL, Sheng P, Ali S, Rothman R, Carlson E, Epstein C. Attenuation of methamphetamine-induced neurotoxicity in copper/zinc superoxide dismutase transgenic mice. f Neurochem 1994; 62: 380-3.

26 Kinouchi H, Epstein CJ, Carlson EJ, Noble LJ, Gafni J, Chan PH. Superoxide dismutase dependent attenuation of blood brain barrier disruption and edema following contusive brain injury. Proc XVIth Symposium on Cerebral Edema and Metabolism May 22-28, 1993; Sendaui, Japan

27 Kubisch HM, Wang J, Luche R, Carlson E, Bray TM, Epstein CJ, et al. Transgenic copper/zinc superoxide dismutase modulates susceptibility to type I diabetes. Proc Natl Acad Sci USA 1994; 91: 9956-9.

28 Sakashita A, Epstein CJ, Carlson E, Koeffler HP. Hematopoietic progenitor cells of transgenic mice with increased copper/zinc-superoxide dismutase activity are resistant to tumor necrosis factor. $\mathcal{F}$ Cell Physiol 1994; 160: 233-8.

29 White CW, Avraham KB, Shanley PF, Groner Y. Transgenic mice with expression of elevated levels of copper-zinc superoxide dismutase in the lungs are resistant to pulmonary oxygen toxicity. F Clin Invest 1991; 87: 2162-8.

30 Feeney L, Berman ER. Oxygen toxicity: membrane damage by free radicals. Invest Ophthalmol 1976; 15: 789-92.

31 Ditelberg J, Sheldon RA, Epstein CJ, Ferriero DM. Brain injury after perinatal hypoxia-ischemia is exacerbated in copper/zinc superoxide dismutase transgenic mice. $f$ Invest Med 1995; 43: 141A

32 Smith LEH, Freedman SF, Foley ED, McLellan A Schwartz $P$. The effect of overexpression of $\mathrm{Cu} / \mathrm{Zn}$ superoxide dismutase on oxygen-induced retinopathy in a transgenic mouse. Invest Ophthalmol Vis Sci 1994; 45 (suppl): 1442.

33 Scott MD, Meshnick SR, Eaton JW. Superoxide dismutaserich bacteria. Paradoxical increase in oxidant toxicity. f Biol Chem 1987; 262: 3640-5.

34 Gyllensten LJ, Hellstrom BE. Experimental approach to the pathogenesis of retrolental fibroplasia. I. Changes to the eye induced by exposure of newborn mice to concentrated oxygen. Acta Paediatr Scand 1954; 43 (suppl 100): oxygen.

35 Henry MM, Tolman BL, Penn JS. Exposure to alternating hypoxia and hyperoxia causes severe proliferative retinopathy in the newborn rat. Invest Ophthalmol Vis Sci 1993; 34 (suppl): 837

36 Reynaud X, Dorey CK. Extraretinal neovascularization induced by hypoxic episodes in the neonatal rat. Invest Ophthalmol Vis Sci 1994; 35: 3169-77.

37 Flynn JT. Retinopathy of prematurity. Pediatr Clin North Am 1987; 34: 1487-516.

38 Kremer I, Kissun R, Nissenkorn I, Ben-Sira I, Garner A. Oxygen-induced retinopathy in newborn kittens. A model for ischemic vasoproliferative retinopathy. Invest Ophthalmol Vis Sci 1987; 28: 126-30.

39 Patz A, Eastham A, Higgenbotham DH, Kleh T. Oxygen studies in retrolental fibroplasia. II. The production of the microscopic changes of retrolental fibroplasia in experimental animals. Am $₹$ Ophthalmol 1953; 36: 1511-22.

40 Michaelson IC, Herz N, Lewkowitz E, Kertesz D. Effect of increased oxygen on the development of the retinal vessels. $B r f$ Ophthalmol 1954; 38: 577-87.

41 Gerschman R, Nadig PW, Snell AC, Nye SW. Effect of high oxygen concentrations on eyes of newborn mice. $\mathrm{Am} \mathcal{F}$ Physiol 1954; 179: 115-8.

42 Gole GA, Browning J, Elts SM. The mouse of oxygeninduced retinopathy: a suitable animal model for angiogenesis research. Doc Ophthalmol 1990; 74: 163-9.

43 Smith LEH, Wesolowski E, McLellan A, Sullivan R, D'Amore PA. Development of a quantifiable reproducible murine model of oxygen induced proliferative retinopathy. Invest Ophthalmol Vis Sci 1993; 34 (suppl): 1448.

44 Smith LEH, Wesolowski E, McLellan A, Kostyk SD, D'Amato R, Sullivan R, et al. Oxygen-induced retinopathy in the mouse. Invest Ophthalmol Vis Sci 1994; 35: 101-11. 